\title{
Refraction measurements and modeling over the Chesapeake Bay during the NATO (TG-51) SAPPHIRE trials, June 2006
}

\author{
Arie N. de Jong, Peter J. Fritz \\ TNO-Defense, Security and Safety; The Hague, The Netherlands
}

\begin{abstract}
Optical refraction tends to occur frequently in the atmospheric boundary layer. Due to a gradient in the temperature as function of height, rays are bending down towards the earth (super-refraction), or up towards to the sky (sub-refraction). As a consequence, images of targets at long range may be distorted and mirages may occur, while the maximum detection range may be affected. In addition the irradiance, received from a point target at a sensor pupil, may increase or decrease due to atmospheric focusing effects. Sub-refraction tends to occur more frequently over sea-paths, as the air is normally cooler than the water. Currently available propagation models, like IRBLEM [1] and EOSTAR [2] adequately describe the mentioned effects for this condition. However sparse data are available for model validation in super-refractive conditions, when the air is warmer than the water. For this reason, the SAPPHIRE trial, (Ship and Atmospheric Propagation Phenomena Infrared Experiment), was organized in the Chesapeake Bay near Washington DC by NATO Task Group TG51 in June 2006. At this location and in this time of the year, the probability for having positive ASTD (Air to Sea Temperature Difference) conditions is high. In the bay a buoy was positioned, on which a set of precision temperature sensors was mounted. They provided as well ASTD values as temperature gradients at a height of $3.7 \mathrm{~m}$. By means of a geodetic theodolite, absolute AOA's (Angle Of Arrival) were measured for a set of lights at various altitudes, located on the other side of the bay at a distance of $16.2 \mathrm{~km}$. The buoy was located at about mid-path position. Positive ASTD conditions did occur on a number of days allowing validation of the values of the AOA, predicted by the models, based upon the meteorological data, simultaneously collected at the buoy. It was found, that the temperature profile, generated by the bulk model for the marine surface layer [3] is incorrect, resulting in deviations in the AOA, compared to the data from the theodolite. A set of empirical temperature profiles has been created, using the ASTD and the gradient in the temperature as function of height as input. One of them provides of predicted AOA values, which fit well with the measurements during the trials period. Errors in the prediction are resulting from the variability of the meteorological conditions, causing inhomogeneities along the path. Furthermore the measurement accuracy was limited due to image blur by atmospheric turbulence in a number of occasions.
\end{abstract}

Keywords: atmospheric propagation, refraction, optical distortion

\section{INTRODUCTION}

It is well known [4], that target detection and observation for long near-horizontal paths is seriously hampered by vertical gradients in the air temperature and thus refractive index (of air). As a consequence, rays are bended upward, when the temperature decreases with height (accordingly the refractive index increases), and downward, when the temperature increases with height. This ray bending is causing optical distortion and associated degradation of the image quality. An example of the effect is shown in Figure 1, in which arrival heights are plotted against departure angles (which we call here: propagation functions) for a fan beam of rays, leaving a camera aperture at an altitude of $7.5 \mathrm{~m}$, towards a receiving plane at a distance of $16.2 \mathrm{~km}$, the actual configuration for our camera and its positioning during SAPPHIRE. In the receiving plane the arrival height is the height at which a certain ray intersects with this plane. In reality, of course, the rays are departing from sources in the receiving plane, arriving under a certain AOA in the camera aperture; this AOA is identical to the departure angle, as rays follow the same paths in both directions. Figure 1 shows five different cases of the propagation function, each for a different temperature profile. For the general function for this profile we have taken: $\mathrm{T}=\mathrm{a}^{*} \operatorname{atan}(\mathrm{h} / \mathrm{b})$. If $\mathrm{T}=\mathrm{T}_{1}$, the temperature difference in ${ }^{\circ} \mathrm{C}$ at a height of $3.7 \mathrm{~m}$ and at zero level is concerned. Consequently we find for the temperature gradient: $d \mathrm{~T} / \mathrm{dh}=\mathrm{T}^{\prime}=(\mathrm{a} / \mathrm{b}) /\left\{1+(\mathrm{h} / \mathrm{b})^{2}\right\}$. For the value of $\mathrm{b}$ we took $1.897 \mathrm{in}$ all cases. For the value of a we took: $1.823\left(\mathrm{~T}_{1}=2.0\right), 0.911\left(\mathrm{~T}_{1}=1.0\right), 0\left(\mathrm{~T}_{1}=0\right.$ and free space $)$ and $-0.911\left(\mathrm{~T}_{1}=-1.0\right)$.

Optics in Atmospheric Propagation and Adaptive Systems $X$

edited by Karin Stein, Anton Kohnle, John D. Gonglewski, Proc. of SPIE

Vol. 6747, 674707, (2007) - 0277-786X/07/\$18 · doi: 10.1117/12.730396

Proc. of SPIE Vol. 6747 674707-1 
The case of free space concerns an atmosphere free condition, without any refraction. If $a=0$, we still have to deal with refraction due to pressure decrease with height, resulting in a certain amount of super-refraction, and the adiabatic decrease in temperature with height of $6^{\circ} \mathrm{C} / \mathrm{km}$, resulting in a small amount of sub-refraction. The calculations of the propagation functions have been carried out with the precision ray-tracing model, described in [4], which is based upon successive calculations of the ray curvature, eliminating the need for defining a layered atmospheric structure. The model allows also the introduction of path-inhomogeneities [5]. The plots in Figure 1 show the super-refractive conditions with $\mathrm{T}_{1}=1.0$ and $2.0^{\circ} \mathrm{C}$, when the AOA's are respectively -371 and $-194 \mu \mathrm{rad}$ for an arrival height of $15.0 \mathrm{~m}$. In the subrefractive condition with $\mathrm{T}_{1}=-1.0^{\circ} \mathrm{C}$, we find two AOA's of -929 and $-1658 \mu \mathrm{rad}$, which indicates a mirage condition. In the case of $\mathrm{T}_{1}=0$ (called: neutral atmosphere), the AOA is found to be $-591 \mu \mathrm{rad}$, which implies, that in the case of $\mathrm{T}_{1}=1.0$ ${ }^{\circ} \mathrm{C}$, the AOA is $220 \mu \mathrm{rad}$ higher: we will observe the source at $220 \mu \mathrm{rad}$ higher elevation than in the neutral condition.

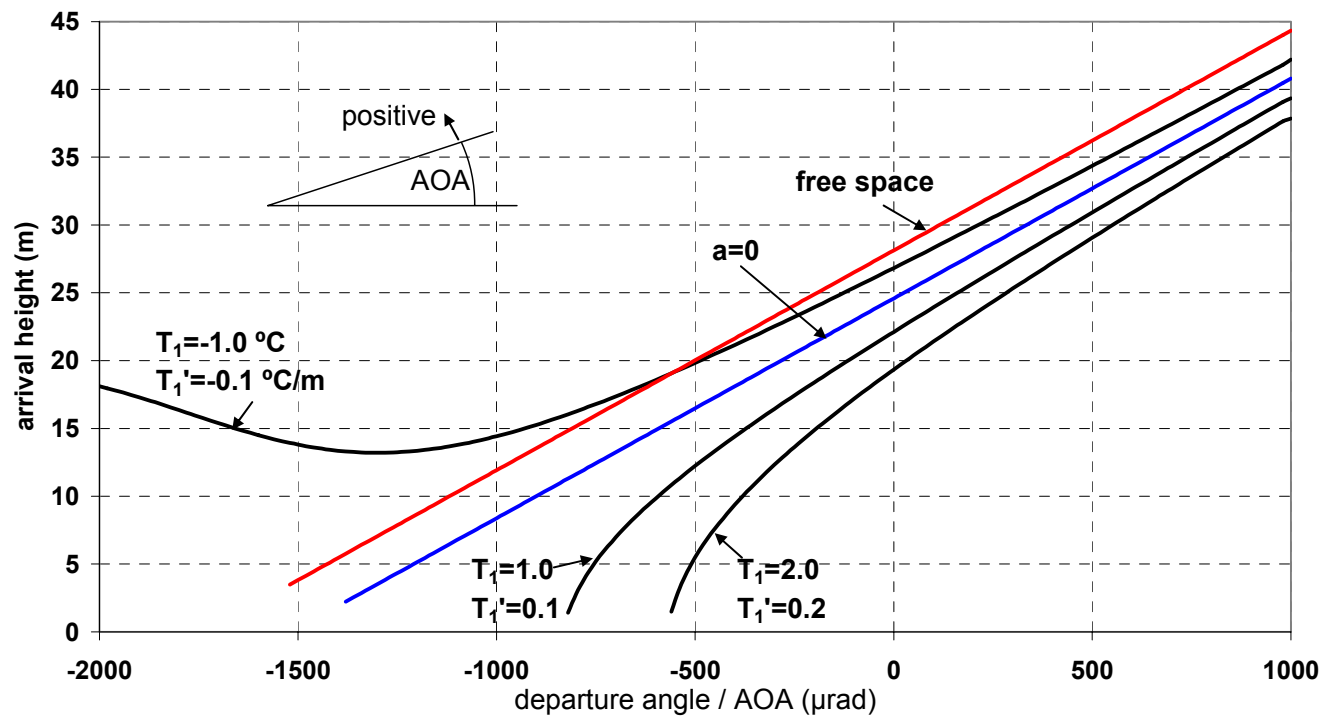

Figure 1. Results of ray-tracings for a path-length of $16.2 \mathrm{~km}$ and a source height of $7.5 \mathrm{~m}$. The type of temperature profile is given by: $\left.\mathrm{T}=\mathrm{a}^{*} \operatorname{atan}(\mathrm{h} / \mathrm{b}) ; \mathrm{T}^{\prime}=\mathrm{dT} / \mathrm{dh}\right)=(\mathrm{a} / \mathrm{b}) /\left\{1+(\mathrm{h} / \mathrm{b})^{2}\right\} ; \mathrm{T}_{1}\left(\right.$ in $\left.{ }^{\circ} \mathrm{C}\right)$ and $\mathrm{T}_{1}{ }^{\prime}\left(\right.$ in $\left.^{\circ} \mathrm{C} / \mathrm{m}\right)$ are taken at an altitude of $3.7 \mathrm{~m}$ and $\mathrm{T}$ concerns the temperature difference at this height with that at zero level.

In most cases in a marine environment, the air temperature decreases with altitude, leading to sub-refractive conditions. The propagation models describe the observed phenomena, such as mirages, horizon diving and refractive gain [6] in these circumstances reasonably well. Simple exponential temperature profiles can be used for quantitative descriptions. The temperature profiles, following from the Monin-Obukhov micro-meteorology theory for the marine surface layer and used in IRBLEM and EOSTAR, perform also quite well in these unstable conditions. For stable conditions however, when the air temperature increases with altitude, less data are available. During the POLLEX trial, carried out in Livorno, Italy, May 2001 [7], super-refraction did occur, leading to distortions for an array of lamps located at a distance of $33 \mathrm{~km}$ [5] and over the horizon target observation for a point source on a boat on 10, 11 and 17 May. Similar effects did occur during the VAMPIRA trials [8], although the fixed sources were located at a rather short distance (about $8 \mathrm{~km}$ ). Denis Dion did analyse data from previous trials ([9] and [10]), while fine tuning the stability functions in the bulk model in order to fit the predicted observation angles to the measured data.

Unfortunately in none of these occasions information was collected on the position (elevation) of the geometrical horizon, defined as the direction of the tangent to the earth at zero level at the location of the sensor. During the SAPPHIRE trial however we were able to arrange a geodetic auto-level instrument with TV sensor, providing day and night AOA's of sources on the opposite side of the Chesapeake Bay. As this trial was arranged in the month of June (2006), there was a reasonable chance of stable atmospheric conditions (positive ASTD) at the CBD site (Chesapeake Bay Detachment of Naval Research Laboratory). In addition we did deploy a buoy in the bay between the sources and the sensors. The main purpose of the sensors on the buoy was to characterize the temperature profile as accurate as possible. Ray-tracing models show that temperature readings with an accuracy of better than $0.01{ }^{\circ} \mathrm{C}$ are required. 


\section{NL EQUIPMENT AT SAPPHIRE}

The SAPPHIRE trial was an international trial, hosted by the NRL, with participants from Canada, Denmark, France, Germany, Italy, The Netherlands, Norway, Poland, South Africa, the United Kingdom and the United States. The objectives of the trial concerned the validation of ship and IR-decoy signature models and propagation models with respect to scintillation and refraction, both in warm environmental conditions. In this paper we limit ourselves to the validation of refraction models. The measurement path over the Chesapeake Bay, about $50 \mathrm{~km}$ SE of Washington DC, is shown in Figure 2. The lamps on Tilghman Island were mounted in a mast on the NRL base at heights of 30.9, 21.4, 13.9 and $5.5 \mathrm{~m}$ above the water level. The TNO receivers, as shown in Figure 3 (middle and right picture), were located on the CBD-site at an altitude of $7.5 \mathrm{~m}$ (coordinates: $38.65350^{\circ} \mathrm{N}, 76.52709^{\circ} \mathrm{W}$ ). The TNO-buoy was positioned at a distance of about $6.12 \mathrm{~km}$ from CBD (coordinates: $38.66613^{\circ} \mathrm{N}, 76.45657^{\circ} \mathrm{W}$ ). The water depth at this location is $11.6 \mathrm{~m}$. A picture of the buoy, floating on three balloons, is shown in Figure 3 (left).

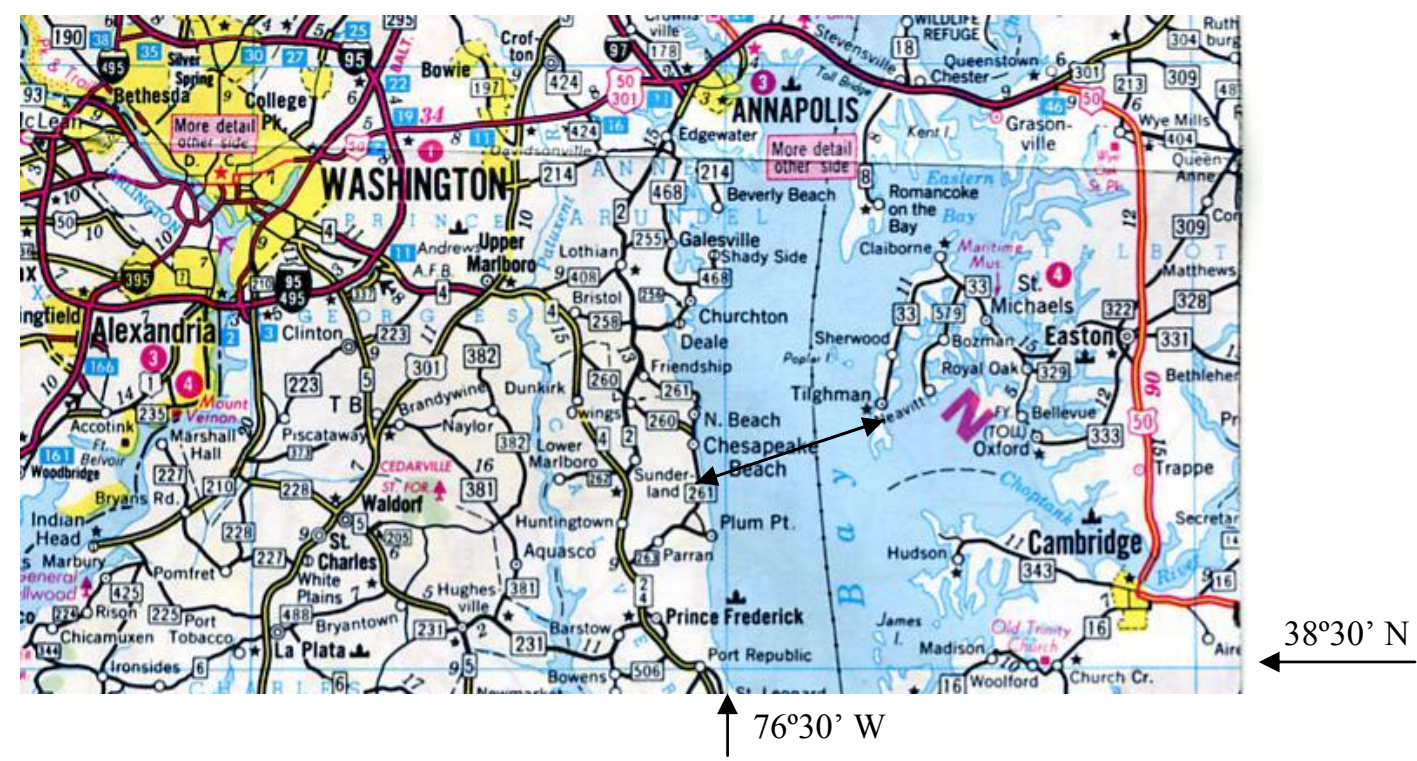

Figure 2. Map of the location of the SAPPHIRE trial at NRL-CBD. The double-arrow shows the measurement path.

In the mast of the buoy one array of five CST temperature and humidity sensors from Campbell, type CS 215, provided with Radiation Shield type 41303, were mounted at a distance of one meter from each other and located at altitudes of 1.34 to 5.34 meter above the water level. In addition an array of eight precision Platinum resistor thermometers from Labfacility, type 146-884, provided with Radiation Shield type 7351 Mini Screen from Vector Instruments, were mounted at a distance of 0.5 meter from each other and positioned at altitudes of 1.55 to 5.05 meter above the water level. Finally the wind-speed was measured by means of a standard device at a height of 5.5 meter above the water. The mast was provided with a red flashing navigation light and a radar corner reflector. The data were stored in two data loggers from Campbell, provided with batteries, loaded in day time by means of solar panels. The buoy was launched with the ship "Aquarius" from the University of Maryland, located at Solomons Island.

The theodolite and the Celestron telescope were mounted on separate tripods under a sun/rain shade in front of a cabin, shared with the South African team. The theodolite (type AT-G2 from Topcon) was provided with a CCD camera (type Sony XC/75CE with a chip-size of $7.95 \times 6.45 \mathrm{~mm}$ ) with a $22.5 \mathrm{~mm}$ objective lens, directly coupled behind the eye-piece. It was found to be necessary to mount two Polaroid filters in front of the telescope in order to reduce the incoming light level in the morning, when looking in the sun-direction. The vertical field of view of the theodolite + CCD camera is 6.40 mrad, while a grabbed image contains 571 lines. The Celestron telescope with $1250 \mathrm{~mm}$ focal length was coupled to a CCD camera (type Sony XC/73CE with $752 \times 582$ pixels and a chip-size of about $4.89 \times 3.64 \mathrm{~mm}$ ). The field of view of a grabbed image of 571 lines is found to be $2.70 \mathrm{mrad}$. The two CCD camera's were synchronized and the images were combined in a standard mixer from Grundig before being recorded on a Panasonic Time Lapse Recorder (type AG-7630). 

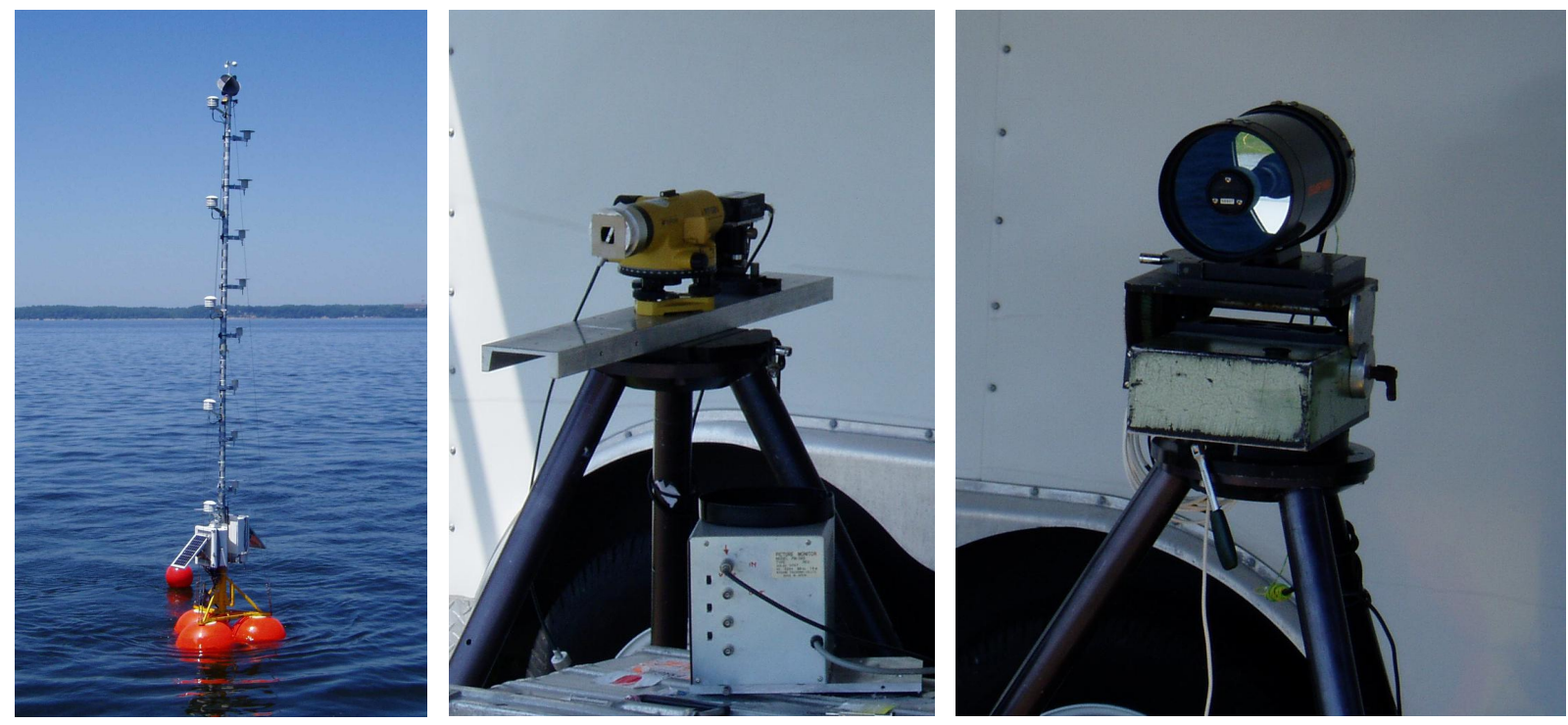

Figure 3. Pictures of the buoy with temperature, humidity and wind-speed sensors (left), the theodolite (middle) and the Celestron $1250 \mathrm{~mm}$ telescope (right), both with TV camera's

Finally a standard weather station was installed near the camera location at an altitude of $8.8 \mathrm{~m}$ above the water level, with sensors for the measurement of temperature, relative humidity, sun- and sky radiance and wind speed and wind direction. Some of the data from these sensors are plotted in Figure 4. The plots show that especially on the first part of the trials period, the air temperature exceeded the value of $25^{\circ} \mathrm{C}$, which means with a water temperature of about $24{ }^{\circ} \mathrm{C} \mathrm{a}$ significantly positive ASTD, for which we were aiming.
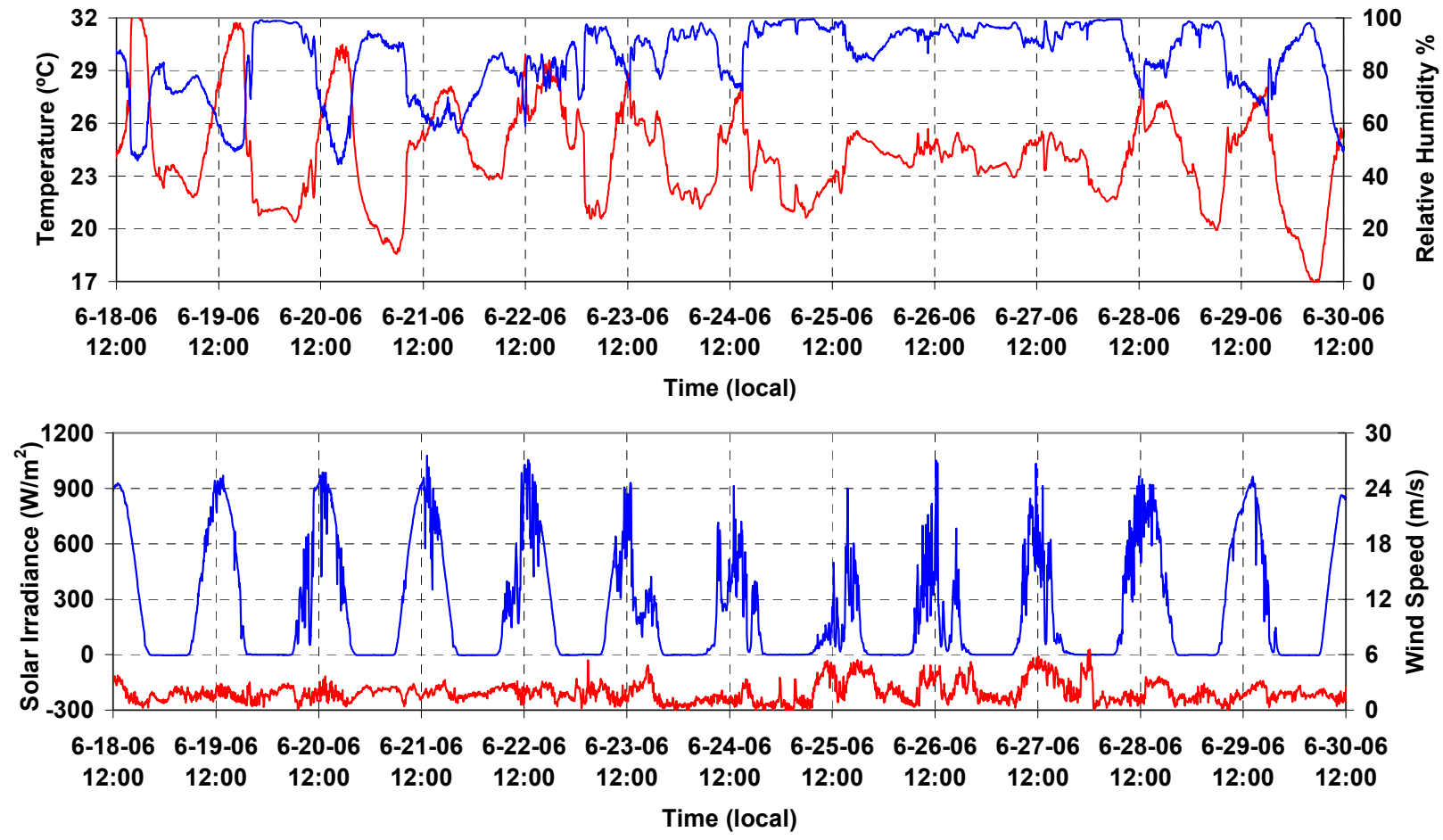

Figure 4. Meteo data from the NL weather station at CBD during the SAPPHIRE trials period: 18-30 June 2006 


\section{BUOY DATA}

The temperature sensors on the buoy were calibrated on the day before the buoy was launched in a shelter from NRL. All sensors were put in a bucket close to each other and the outputs were averaged over a sufficiently long period. All offsets were noted and associated corrections were made for the measurements during the trial. Most offsets were of the order of several hundreds of a degree $\mathrm{K}$. In the data logger, data were averaged over one minute and one sample per minute was recorded. It appeared from the data during the trial, that the output from the PT and CT sensor arrays, mounted on the two opposite sides of the mast, were generally very close in agreement. Figure 5 shows temperature data (averaged over 10 minutes and sampled each five minutes) for four of the five CT sensors on the buoy for the whole trials period. The bottom sensor was found to be less reliable due to frequent exposure by water-spray in rough water. The plot shows that the maximum temperatures for the days 19-22 June, are less than those from the shore-located sensor.

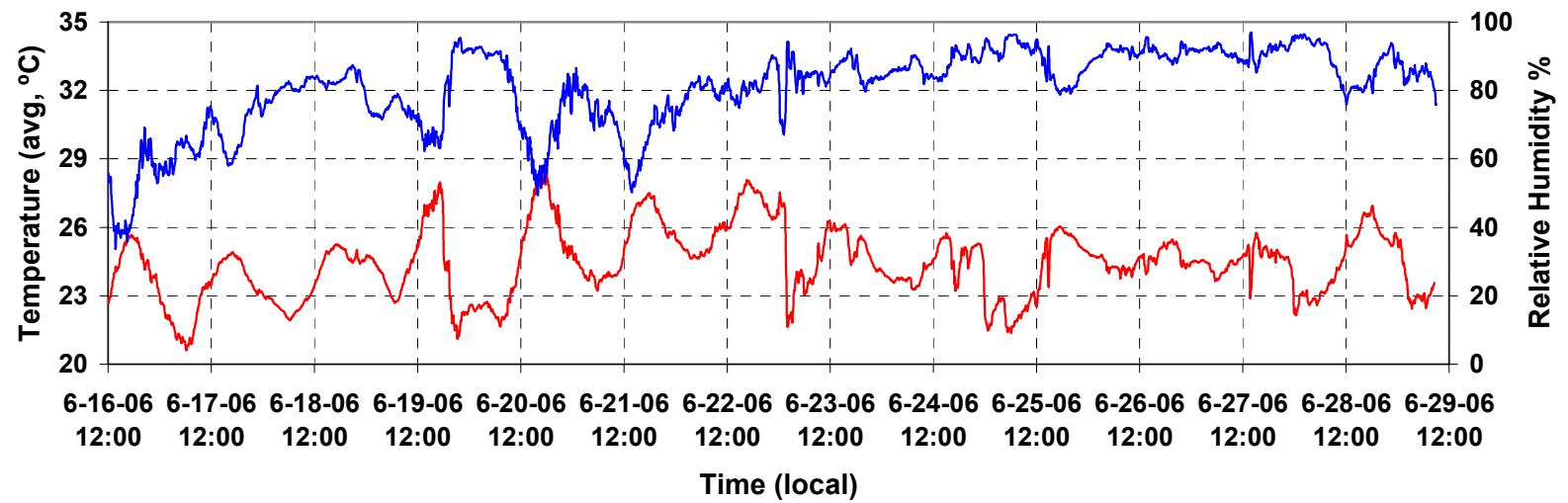

Figure 5. Temperature (CT1 to CT4 average) and Relative Humidity (CT3), measured at the TNO buoy

This is shown in some more detail in Figure 6 (left), where also the prevailing wind direction is shown (West). The plots show, that the temperature increase (50\% point) for the shore sensor occurs about one hour earlier than that for the buoy sensor, which corresponds to the wind direction. It is striking, that the relative humidity on the shore is generally higher than that on the buoy. A big question was if the temperature data from the sensors at different heights would allow a reliable retrieval of the temperature gradient. For further clarification of this question, plots of three CT sensors are shown in Figure 6 (right) for a few hours on the $19^{\text {th }}$ of June. In these plots data were averaged over one minute and sampled each minute. The temperature gradient during this period is of the order of $0.1 \% \mathrm{~m}$. Very striking is the nearly periodical and synchronous fluctuation of each temperature with a period of about 15 minutes. It was shown that these fluctuations did occur at several occasions. Apparently there is a serious large scale of turbulent motion occurring for the air-mass over the Chesapeake Bay. The magnitude of the fluctuation is of the order of several tens of degrees, which is large enough to create optical ray bending and potentially additional blurring.
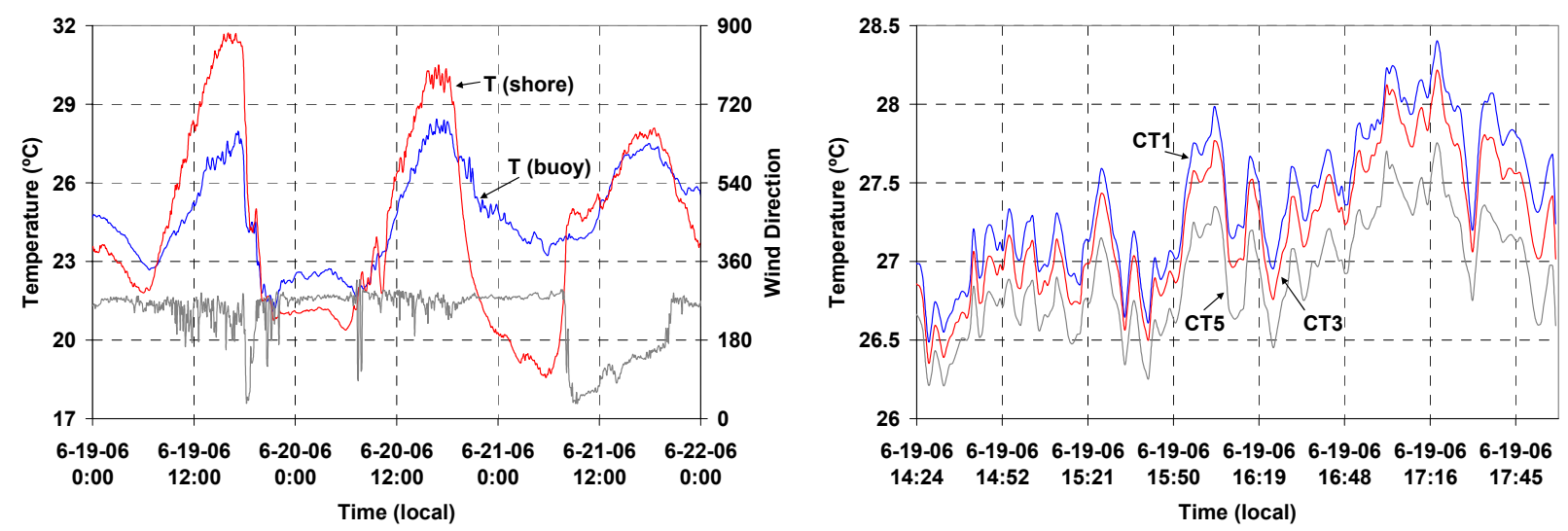

Figure 6. Comparison of temperature plots from shore and buoy sensors (left, including wind-direction); plots of three temperature recordings at $5.34 \mathrm{~m}(\mathrm{CT} 1), 3.34 \mathrm{~m}$ (CT3) and $1.34 \mathrm{~m}$ (CT5) above the water (right, at buoy) 
The temperature gradient (T-gradient or T') has been obtained by subtracting the average temperature recordings from the $\mathrm{CT} 1+\mathrm{CT} 2$ sensors and the CT3+CT4 sensors divided by 2 . This was done because of the presence of strong fluctuations in certain periods. The T-gradients from the CT sensors were compared with those from the PT sensors and found to be in general agreement, although the PT based gradients showed more fluctuations, probably because of the fact that they were more sensitive to water exposure (during rain). Figure 7 shows a plot of the T-gradient from the CT sensors for the first part of the trials period together with the ASTD, both measured at a height of $3.7 \mathrm{~m}$. The ASTD has been obtained by averaging the recordings of the CT1 to CT4 sensors, time-averaged over 10 minutes and sampled once in 5 minutes. From this average air temperature at $3.7 \mathrm{~m}$, the value of the air temperature at zero level was subtracted. For this zero level temperature we took $23{ }^{\circ} \mathrm{C}$ as a kind of average skin temperature of the water. The value of T-gradient is mostly positive, in synchronism with the ASTD. However large ASTD values do not always imply a large value of T-gradient (see 21 and 22 June). The maximum T-gradient value is about $0.2 \%$ on 20 June.

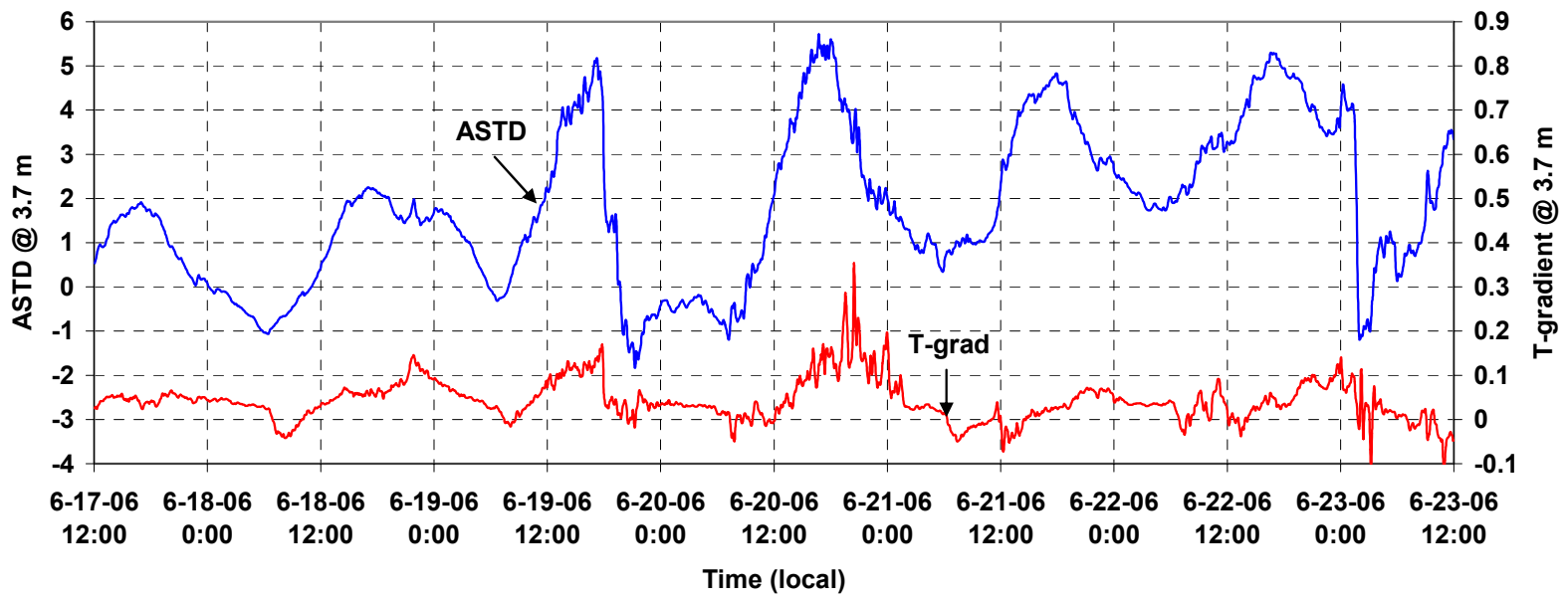

Figure 7. Plots of ASTD $(\mathrm{K})$ and temperature gradient $(\mathrm{K} / \mathrm{m})$ for period with considerable positive ASTD conditions

\section{THEODOLITE DATA}

Some examples of images, taken with both camera systems, are shown in Figure 8. In the images of the theodolite the cross-hair, aiming at the geometrical horizon, is clearly shown, while the four sources in the NRL mast at $16.2 \mathrm{~km}$ on the opposite side of the Bay, are moving up and down due to ray bending. It is noted, that the sources could only be perceived in moderate to good visibility conditions. At night, the cross-hair could not be seen; as long as the camera behind the theodolite is not touched, we may assume that the aiming point stays to the same. In the morning we had reduced contrast due to sun and sky radiation. The imagery shows typical variations in the AOA for different ASTD conditions.
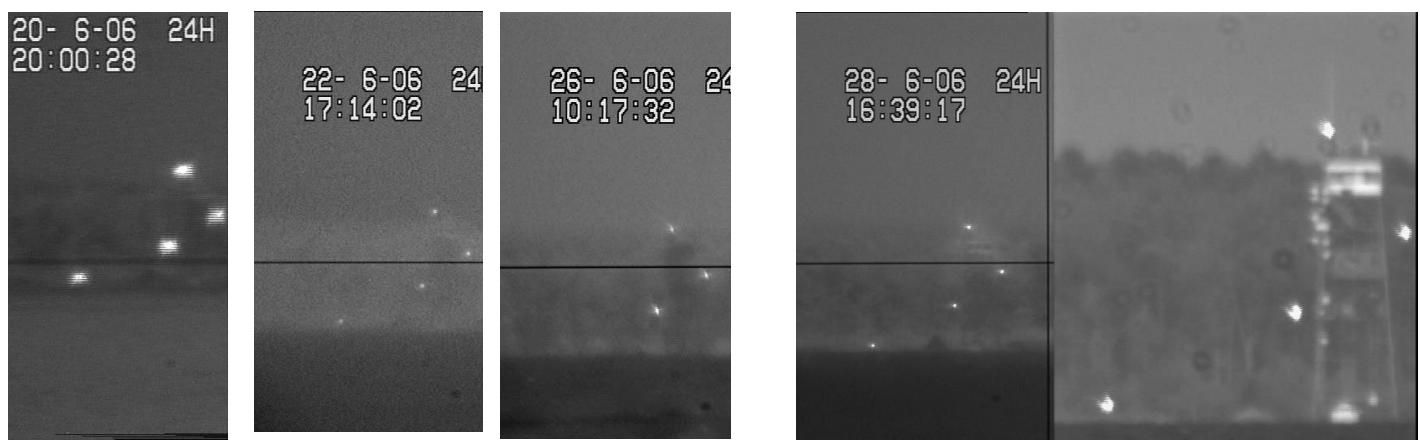

Figure 8. Examples of imagery through the theodolite (four left images) and Celestron telescope (most right image); left we see super-refraction; the $3^{\text {rd }}$ picture from the left shows sub-refraction (the lowest source is invisible) 
Figure 9 shows AOA values for the most interesting part of the trial, together with the AOA levels for neutral conditions (including pressure and adiabatic temperature decrease with height, but ASTD $=0$ ). The neutral levels are: $+0.389,-0.196$, -0.659 and $-1.177 \mathrm{mrad}$ for respectively $\mathrm{u}_{1}, \mathrm{u}_{2}, \mathrm{u}_{3}$ and $\mathrm{u}_{4}$. In free space, $\mathrm{u} 1-\mathrm{u} 4$ would be: $+0.173,-0.414,-0.877$ and -1.396 mrad. For clarity the $u_{2}$ data have been removed. The largest AOA deviations clearly occur on the $20^{\text {th }}$ of June, when the values of $u_{1}$ to $u_{4}$ all exceed the level of $1.0 \mathrm{mrad}$. It is noted, that the estimated RMS error of the theodolite with camera is about $30 \mu \mathrm{rad}$ for low turbulence conditions, which corresponds to a spot size of about $0.5 \mathrm{~m}$ at a distance of $16.2 \mathrm{~km}$. Over the Chesapeake Bay however, turbulence was frequently quite heavy, causing an increase in error for the AOA value, determined from the imagery. It is clear, that the maximum AOA values on the $21^{\text {st }}$ and $22^{\text {nd }}$ of June do not agree with the large ASTD values on those days, but correspond better with the T-gradient values, as appears from Figure 7.

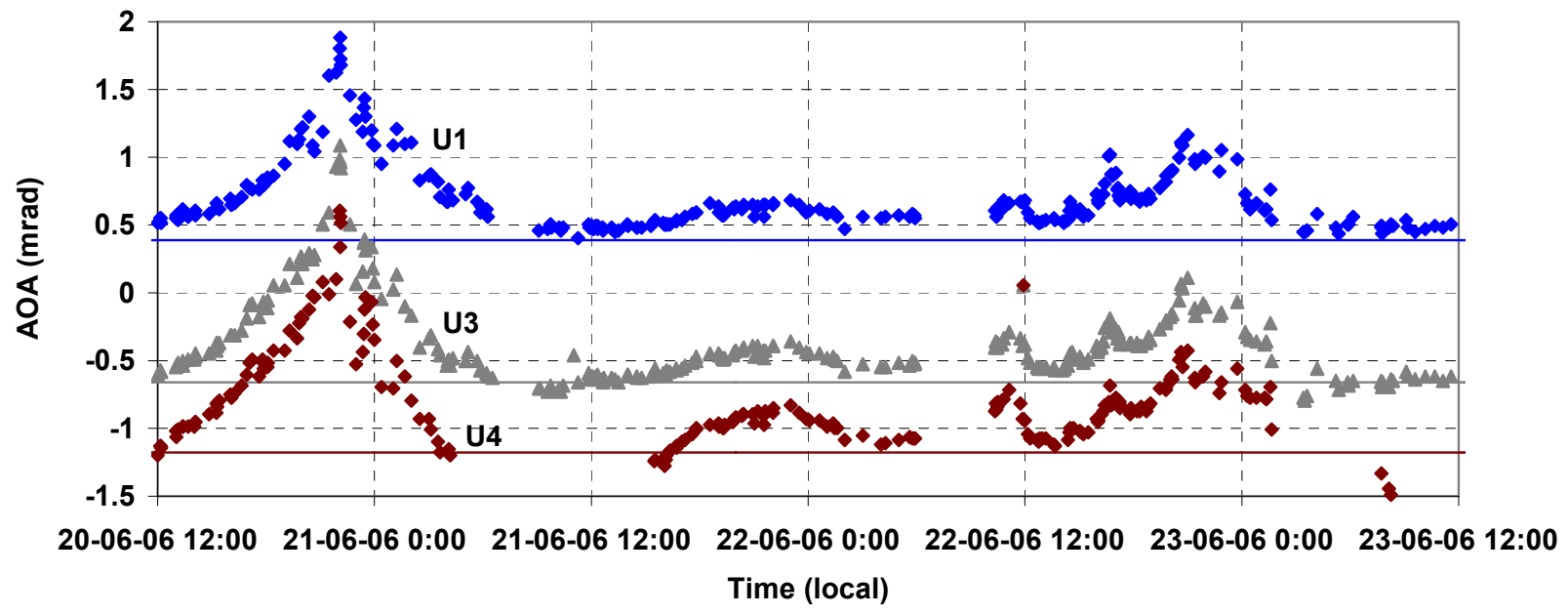

Figure 9. Plots of the AOA for three of the four sources compared to their neutral levels during a part of the trial.

\section{MODELING T-PROFILES AND AOA'S}

In this section we will introduce a number of temperature profiles, all of them in accordance with the boundary condition for the ASTD T and the temperature gradient T' at an altitude of $3.7 \mathrm{~m}$. For reasons of simplicity we have chosen here for analytical functions, of which some examples are shown in Figure 10 for the boundary conditions: $\mathrm{T}=1 \mathrm{~K}$ and $\mathrm{T}^{\prime}=0.1 \mathrm{~K} / \mathrm{m}$ at $3.7 \mathrm{~m}$ altitude. Each of the analytical functions is determined by two parameters a and $\mathrm{b}$. One of the plots shown is obtained from the bulk model, as used in the EOSTAR model, in which we cannot insert a value for T', but where a set of meteorological parameters has to be specified.
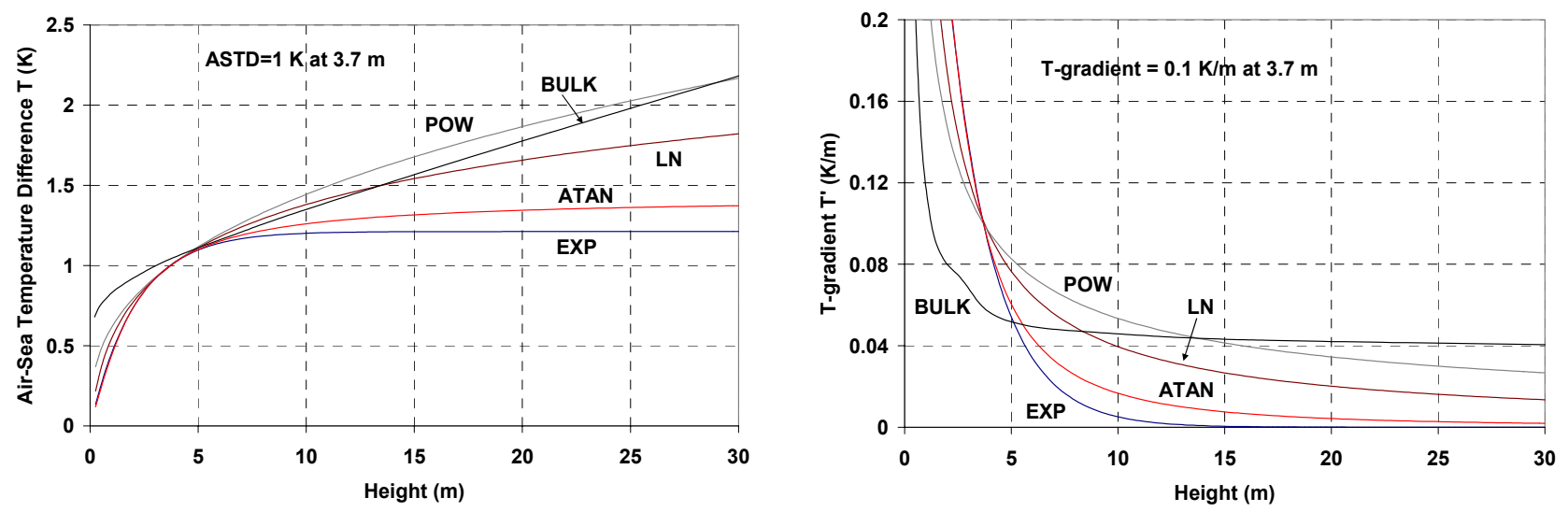

Figure 10. Examples of different T-profiles in modeling efforts; (left, for ASTD $=1 \mathrm{~K}$ at $3.7 \mathrm{~m}$ ) and T-gradient profiles (right, for T-gradient $=0.1 \mathrm{~K} / \mathrm{m}$ at $3.7 \mathrm{~m}$ ) 
The functions, investigated in the modeling efforts, are the following:

$\begin{array}{lll}\text { EXP: } & \mathrm{T}=-(\mathrm{b} / \mathrm{a})^{*}\left\{\exp \left(-\mathrm{a}^{*} \mathrm{~h}\right)-1\right\} & \mathrm{T}{ }^{\prime}=-\mathrm{b}^{*} \exp \left(-\mathrm{a}^{*} \mathrm{~h}\right) \\ \text { QUAD: } & \mathrm{T}=\mathrm{a}^{*}\left(\mathrm{~h}^{\wedge} 1.5\right) /\left\{1+\mathrm{b}^{*}\left(\mathrm{~h}^{\wedge} 1.5\right)\right\} & \mathrm{T}^{\prime}=1.5^{*} \mathrm{a}^{*}\left(\mathrm{~h}^{\wedge} 0.5\right) /\left\{1+\mathrm{b}^{*}\left(\mathrm{~h}^{\wedge} 1.5\right)\right\}^{\wedge} 2 \\ \text { ATAN: } & \mathrm{T}=\mathrm{a}^{*} \mathrm{atan}(\mathrm{h} / \mathrm{b}) & \mathrm{T}=(\mathrm{a} / \mathrm{b}) /\{1+(\mathrm{h} / \mathrm{b})\}^{\wedge} 2 \\ \text { LN: } & \mathrm{T}=\mathrm{a}^{*} \ln \left(1+\mathrm{b}^{*} \mathrm{~h}\right) & \mathrm{T}=\mathrm{a}^{*} \mathrm{~b} /\left(1+\mathrm{b}^{*} \mathrm{~h}\right) \\ \text { POW: } & \mathrm{T}=\mathrm{a}^{*} \mathrm{~h}^{\wedge} \mathrm{b} & \mathrm{T}^{\prime}=\mathrm{b}^{*} \mathrm{a}^{*} \mathrm{~h}^{\wedge}(\mathrm{b}-1)\end{array}$

For each combination of $\mathrm{T}$ and $\mathrm{T}$ ' values the parameters $\mathrm{a}$ and $\mathrm{b}$ have to be determined. A number of examples for $\mathrm{a}$ and $\mathrm{b}$ values for the different T-profile functions are shown in Table 1. The functions EXP, QUAD and ATAN approach a certain limit of $\mathrm{T}$ for large altitudes $\mathrm{h}$, while the functions $\mathrm{LN}$ and POW stay increasing. As Figure 10 shows the POW profile has the highest T-gradient value for altitudes above 5 meter, which implies a stronger ray-bending (smaller $\mathrm{KC}$ ).

Table 1. Values for $\mathrm{a}$ and $\mathrm{b}$ parameters for different $\mathrm{T}$-profile functions with boundary conditions for $\mathrm{T}$ and $\mathrm{T}^{\prime}$ at $\mathrm{h}=3.7 \mathrm{~m}$.

\begin{tabular}{|c|c|c|c|c|c|c|c|c|c|c|c|}
\hline \multicolumn{2}{|c|}{ T-profile } & \multicolumn{2}{c|}{ EXP } & \multicolumn{2}{c|}{ QUAD } & \multicolumn{2}{c|}{ ATAN } & \multicolumn{2}{c|}{ LN } & \multicolumn{2}{c|}{ POW } \\
\hline $\mathrm{T}$ & $\mathrm{T}$ & $\mathrm{a}$ & $\mathrm{b}$ & $\mathrm{a}$ & $\mathrm{b}$ & $\mathrm{a}$ & $\mathrm{b}$ & $\mathrm{a}$ & $\mathrm{b}$ & $\mathrm{a}$ & $\mathrm{b}$ \\
\hline 0.5 & 0.05 & 0.471 & 0.285 & 0.285 & 0.429 & 0.456 & 1.897 & 0.203 & 2.9 & 0.308 & 0.37 \\
\hline 0.5 & 0.1 & 0.155 & 0.178 & 0.142 & 0.144 & 0.767 & 4.850 & 0.90 & 0.20 & 0.19 & 0.74 \\
\hline 1.0 & 0.05 & 0.749 & 0.799 & 1.139 & 0.999 & 0.759 & 0.962 & 0.406 & 2.9 & 0.785 & 0.185 \\
\hline 1.0 & 0.1 & 0.471 & 0.571 & 0.570 & 0.429 & 0.911 & 1.897 & 0.41 & 2.8 & 0.616 & 0.37 \\
\hline 1.0 & 0.2 & 0.155 & 0.355 & 0.285 & 0.144 & 1.535 & 4.851 & 1.68 & 0.22 & 0.38 & 0.74 \\
\hline 2.0 & 0.1 & 0.749 & 1.598 & 2.278 & 0.999 & 1.519 & 0.962 & 0.38 & 50 & 1.57 & 0.185 \\
\hline 2.0 & 0.2 & 0.471 & 1.142 & 1.139 & 0.429 & 1.823 & 1.897 & 0.80 & 3.0 & 1.233 & 0.37 \\
\hline
\end{tabular}

For all listed T-profiles the AOA's $u$ have been calculated (method described in [4]), as well as $\Delta \mathrm{u}$, being the difference of $u$ and the value of $u$ for the neutral atmosphere (includes pressure and adiabatic temperature decrease with height). We found a simple general analytical expression for each case, giving an approximate value for $\Delta \mathrm{u}$ :

$$
\Delta \mathrm{u}=\mathrm{k}^{*}\left\{\left(\mathrm{~T}^{\prime}\right)^{\mathrm{m}}\right\} /\left(\mathrm{T}^{\mathrm{n}}\right)
$$

This approximation is only valid for positive ASTD conditions within certain limits of T' and T values: T' $<0.2 \mathrm{~K} / \mathrm{m}$ and $\mathrm{T}<3 \mathrm{~K}$. We have included the ray tracings for the assumption of the profile conform the bulk model, where only the temperature plays a role. Thus we took for the exponent $\mathrm{m}$ the value 0 in this case. For all other T-profiles the parameters $\mathrm{k}, \mathrm{m}$ and $\mathrm{n}$ are listed in Table 2 for the four sources at the altitudes $30.9 \mathrm{~m}, 21.4 \mathrm{~m}, 13.9 \mathrm{~m}$ and $5.5 \mathrm{~m}$, at $16.2 \mathrm{~km}$ range and a receiver at $7.5 \mathrm{~m}$, resulting in angular AOA differences: $\Delta \mathrm{u}_{1}, \Delta \mathrm{u}_{2}, \Delta \mathrm{u}_{3}$ and $\Delta \mathrm{u}_{4}$. The formula (1) allows direct calculation of the AOA difference for given conditions of temperature and temperature gradient as measured on the buoy.

Table 2. Table with parameters $\mathrm{k}, \mathrm{m}$ and $\mathrm{n}$ in the formula for $\Delta \mathrm{u}: \Delta \mathrm{u}=\mathrm{k}^{*}\left\{\left(\mathrm{~T}^{\prime}\right)^{\mathrm{m}}\right\} /(\mathrm{T})^{\mathrm{n}}$

\begin{tabular}{|c|c|c|c|c|c|c|c|c|c|c|c|c|}
\hline & \multicolumn{4}{|c|}{$\Delta \mathrm{u}_{1}$} & \multicolumn{4}{c|}{$\Delta \mathrm{u}_{2}$} & \multicolumn{3}{c|}{$\Delta \mathrm{u}_{3}$} & \multicolumn{3}{c|}{$\Delta \mathrm{u}_{4}$} \\
\hline T-profile & $\mathrm{k}$ & $\mathrm{m}$ & $\mathrm{n}$ & $\mathrm{k}$ & $\mathrm{m}$ & $\mathrm{n}$ & $\mathrm{k}$ & $\mathrm{m}$ & $\mathrm{n}$ & $\mathrm{k}$ & $\mathrm{m}$ & $\mathrm{n}$ \\
\hline BULK & 0.54 & 0 & -2.28 & 0.57 & 0 & -2.23 & 0.61 & 0 & -2.16 & 0.74 & 0 & -1.93 \\
\hline EXP & 98 & 3.39 & 2.4 & 52 & 2.81 & 1.94 & 23.8 & 2.17 & 1.36 & 6.6 & 1.22 & 0.65 \\
\hline QUAD & 3.8 & 1.65 & 0.72 & 4.5 & 1.55 & 0.62 & 4.5 & 1.34 & 0.49 & 3.1 & 0.87 & 0.25 \\
\hline ATAN & 6.1 & 1.75 & 0.79 & 6.5 & 1.62 & 0.92 & 6.0 & 1.41 & 0.84 & 4.2 & 0.98 & 0.64 \\
\hline LN & 8.4 & 1.51 & 0.59 & 8.1 & 1.41 & 0.52 & 7.2 & 1.27 & 0.43 & 5.6 & 1.02 & 0.29 \\
\hline POW & 13.4 & 1.57 & 0.62 & 11.5 & 1.45 & 0.52 & 10.0 & 1.33 & 0.43 & 7.2 & 1.09 & 0.27 \\
\hline
\end{tabular}


Sample plots of $\Delta \mathrm{u}_{2}$ and $\Delta \mathrm{u}_{4}$ are shown in Figure 11 for the POW and EXP T-profiles as function of T' (@3.7 m), for ASTD's of 1, 2 and 4K (@3.7 m), calculated with the precision ray-tracing scheme. As could be expected, the EXP profile does hardly give any refraction for the sources at higher altitudes. The plots for the POW profile show a rather linear relationship between $\Delta \mathrm{u}$ and T' and only a minor influence of the ASTD value. Figure 12 (left) shows comparative plots of $\Delta \mathrm{u}_{1}$ versus ASTD for a constant ratio of $\mathrm{T}^{\prime} / \mathrm{T}=0.1 \mathrm{~m}^{-1}$, using the approximation formula (1). Extreme AOA's appear for the BULK profile for ASTD values greater than $1 \mathrm{~K}$ at $3.7 \mathrm{~m}$ height. It is clear that this kind of super-refraction is un-realistic: be careful in using the BULK related profile. We also find the differences in AOA's between the profiles EXP, ATAN and POW, all in agreement, what we might expect on the basis of the profiles for T and T', shown in Figure 10. For the source at higher altitude, associated with $\Delta \mathrm{u}_{1}$, the EXP and ATAN profiles produce too small AOA's. The POW profile seems to be the only one, producing $\Delta$ u's of the order of 1 mrad for ASTD's of several degrees K.
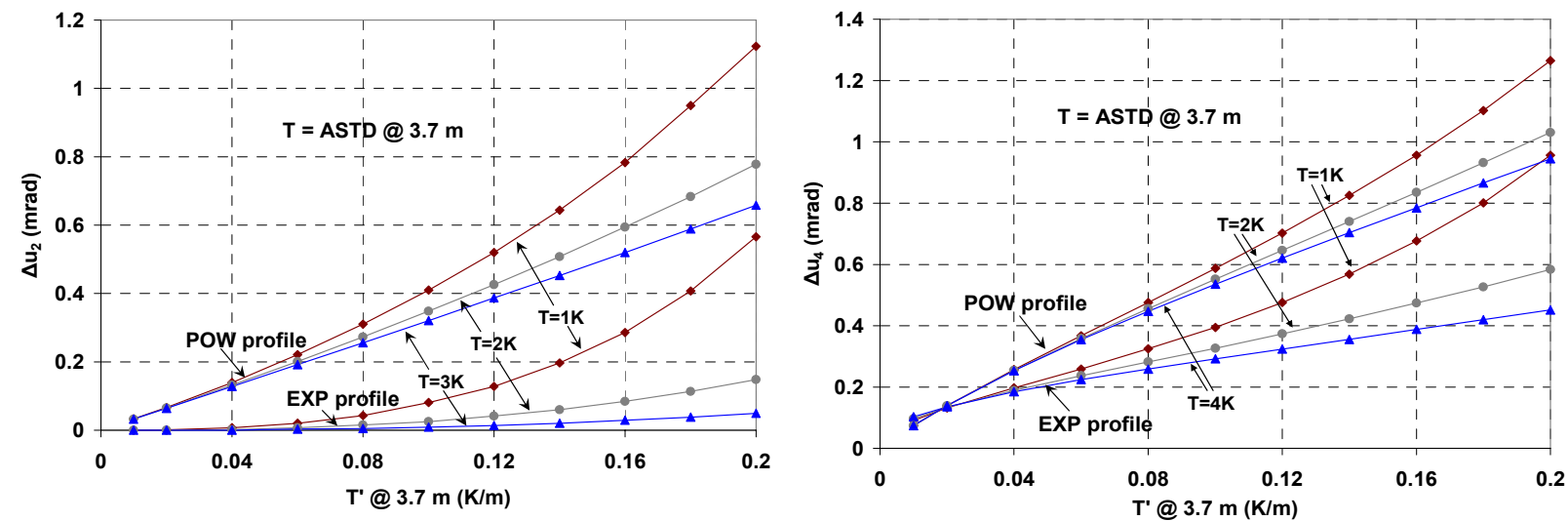

Figure 11. $\Delta \mathrm{u}_{2}$ (left) and $\Delta \mathrm{u}_{4}$ (right) as function of the temperature gradient for the POW and EXP T-profiles and ASTD values of 1,2 and $4 \mathrm{~K}$, calculated with the precision ray tracing program.

Distortion is defined in this paper as the ratio of the vertical angular separation of two neighboring sources with a certain T-profile and a similar separation of these sources in neutral atmospheric conditions: $D_{1}=\left(u_{1}-u_{2}\right) /\left(u_{1}-u_{2}\right)_{n}, D_{2}=\left(u_{2}-u_{3}\right) /\left(u_{2}-\right.$ $\left.\mathrm{u}_{3}\right)_{\mathrm{n}}$ and $\mathrm{D}_{3}=\left(\mathrm{u}_{3}-\mathrm{u}_{4}\right) /\left(\mathrm{u}_{3}-\mathrm{u}_{4}\right)_{\mathrm{n}}$. In fact, even a neutral atmosphere has a tiny distortion compared to the refraction-less free space condition, but this distortion is neglected here. In conditions of positive ASTD (as in Figure 8 left) the angular separation tends to decrease, and thus the values of $D_{1}, D_{2}$ and $D_{3}$ become smaller than one. This behavior is clearly illustrated in Figure 12 (right), where $D_{1}, D_{2}$ and $D_{3}$ are plotted versus ASTD for a constant ratio of $T^{\prime} / T=0.1 \mathrm{~K} / \mathrm{m}$ for the EXP profile. The plots show that the distortion for $\mathrm{D}_{3}$ is the strongest. For $\mathrm{D}_{1}$ the distortion is less, as the EXP profile has a minor effect for altitudes above $10 \mathrm{~m}$. The situation for the POW profile is in better harmony for all source heights.
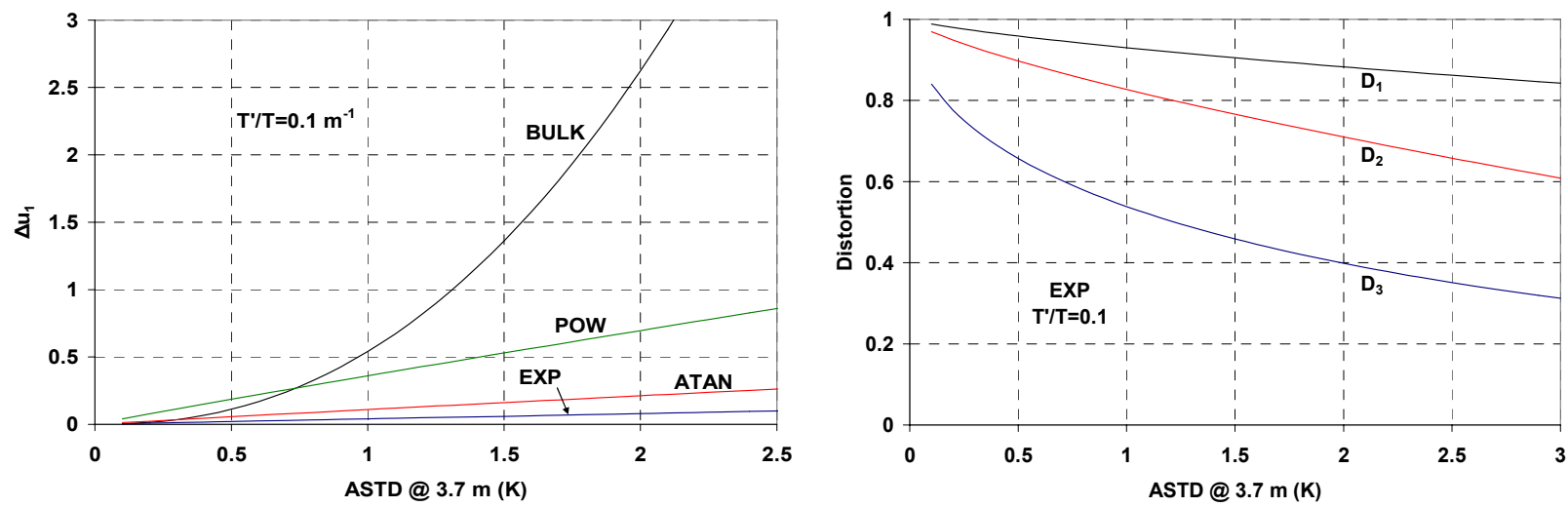

Figure 12. Left: Difference in AOA: $\Delta \mathrm{u}_{4}$ as function of ASTD for various T-profiles; Right: Distortions $\mathrm{D}_{1}-\mathrm{D}_{3}$ for the EXP T-profile as function of ASTD. In both cases we used the approximating formula (1) and $T^{\prime} / T=0.1 \mathrm{~m}^{-1}$. 


\section{MODEL VALIDATION}

In relation to the preliminary results from the modeling, we compare here the behavior of the measured and modeled value of AOA difference $\Delta \mathrm{u}$ as function of time. For modeling purpose we took values of $\mathrm{T}$ and $\mathrm{T}$ ' at each time stamp, that a picture was collected, from which the value of $\Delta \mathrm{u}_{1}$ to $\Delta \mathrm{u}_{4}$ was obtained. From $\mathrm{T}$ and $\mathrm{T}$ ', the parameters $\mathrm{k}, \mathrm{m}$ and $\mathrm{n}$ were determined for the POW profile (and other profiles). By using formula (1) the values of $\Delta \mathrm{u}_{1}$ to $\Delta \mathrm{u}_{4}$ were obtained, to be plotted parallel to the measured data. A combined measured and modeled plot of $\Delta \mathrm{u}_{4}$ for the complete trials period is shown in Figure 13. Note that the modeled $\Delta \mathrm{u}_{4}$ plot is shown according to a shifted scale (right). Although the absolute values of the measured and modeled plots differ sometimes, the general trends correspond strikingly well.

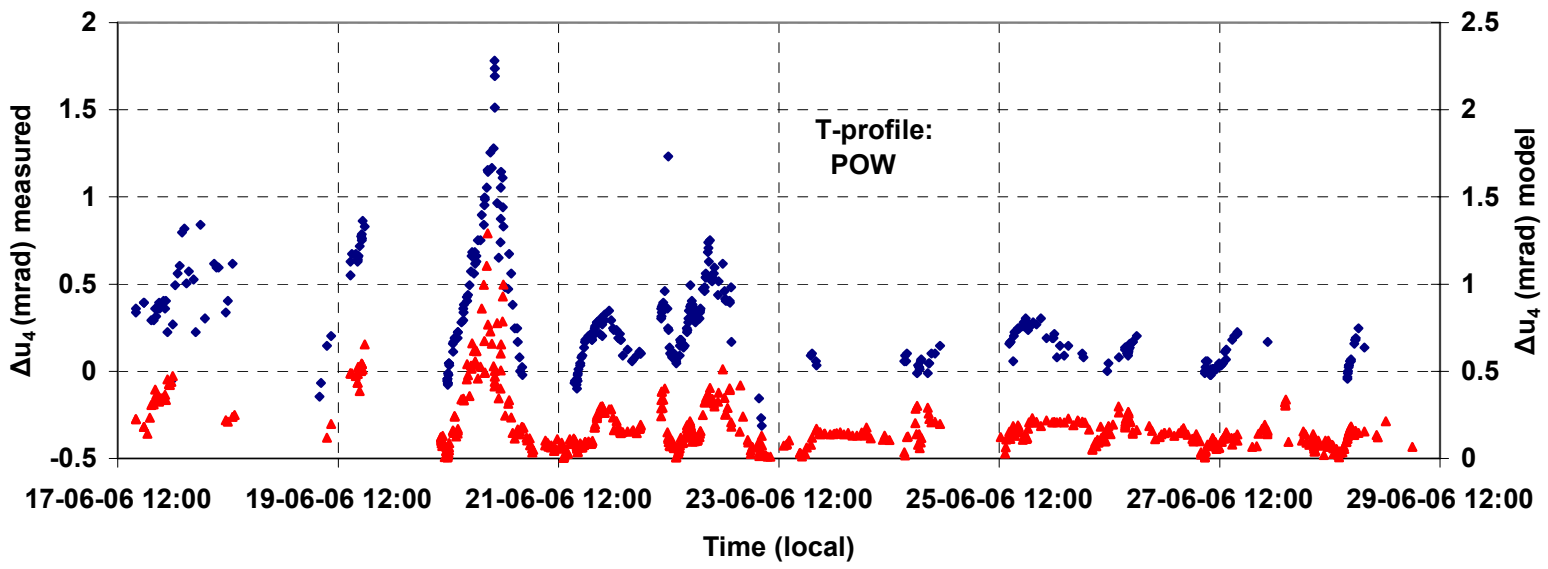

Figure 13. $\Delta \mathrm{u}_{4}$ measured (diamonds) and modeled (formula (1), triangles) with POW T-profile during SAPPHIRE trial

It is noted however, that the similar plots of $\Delta \mathrm{u}_{1}$ show less agreement, as is illustrated in Figure 14 (left) for a limited part of the trials period. The modeled $\Delta \mathrm{u}_{1}$ value is about a factor two lower than the measured value. Compared to the case of a different T-profile, for example the ATAN profile (see Figure 14, right), the situation for the case of the POW profile is much better. The values of ATAN based $\Delta \mathrm{u}_{1}$ are too small for the source at the highest position, which corresponds to the previous remarks on the ATAN profile (see Figure 10). It is also clear, that the importance of the value of T is much smaller than the value of T' for the magnitude of the AOA. This is shown for the measured as well as for the modeled AOA differences. In a similar way we found (not shown here), that the EXP and QUAD profiles gave AOA differences, much smaller than the POW profile and the measured data. Similar to the plot of $\Delta \mathrm{u}_{1}$ in Figure 14 (left), plots of $\Delta \mathrm{u}_{3}$ and $\Delta \mathrm{u}_{4}$ are shown for the same period and the POW profile in Figure 15. This figure shows, that the measured and modeled plots follow correspond well, creating confidence in the temperature and temperature gradient measurements at the buoy and showing that the temperature profile is rather homogeneous along the path.
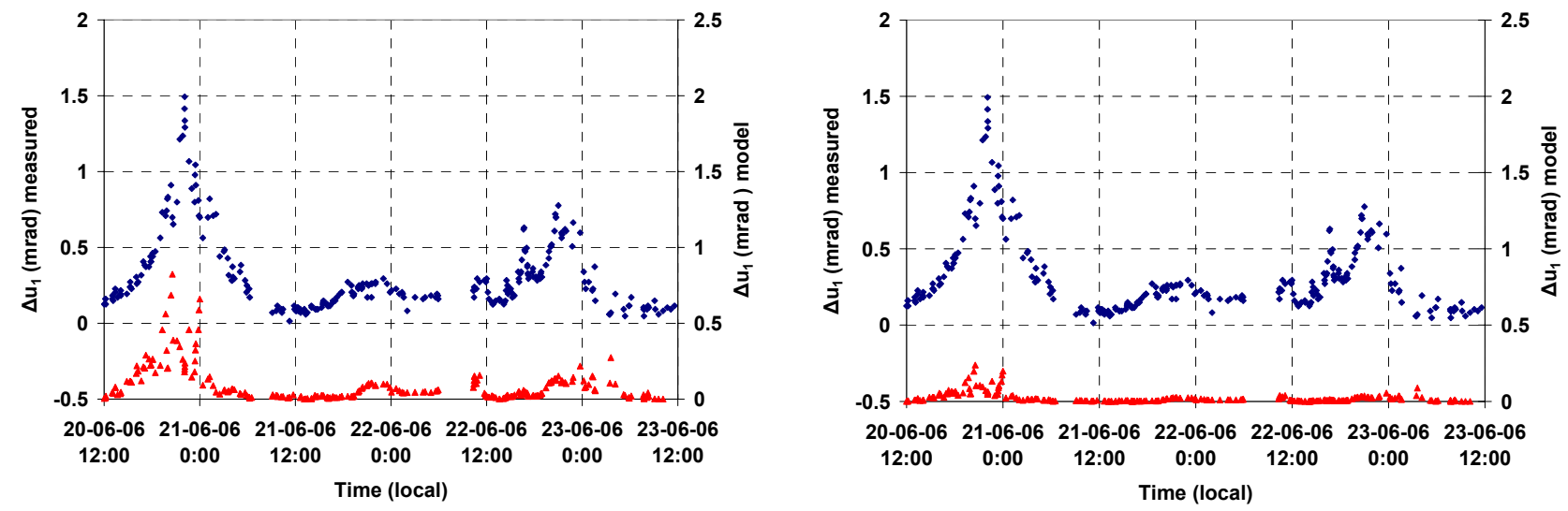

Figure 14. $\Delta \mathrm{u}_{1}$ measured and modeled (formula (1)) with POW (left) and ATAN (right) profile during part of the trial 

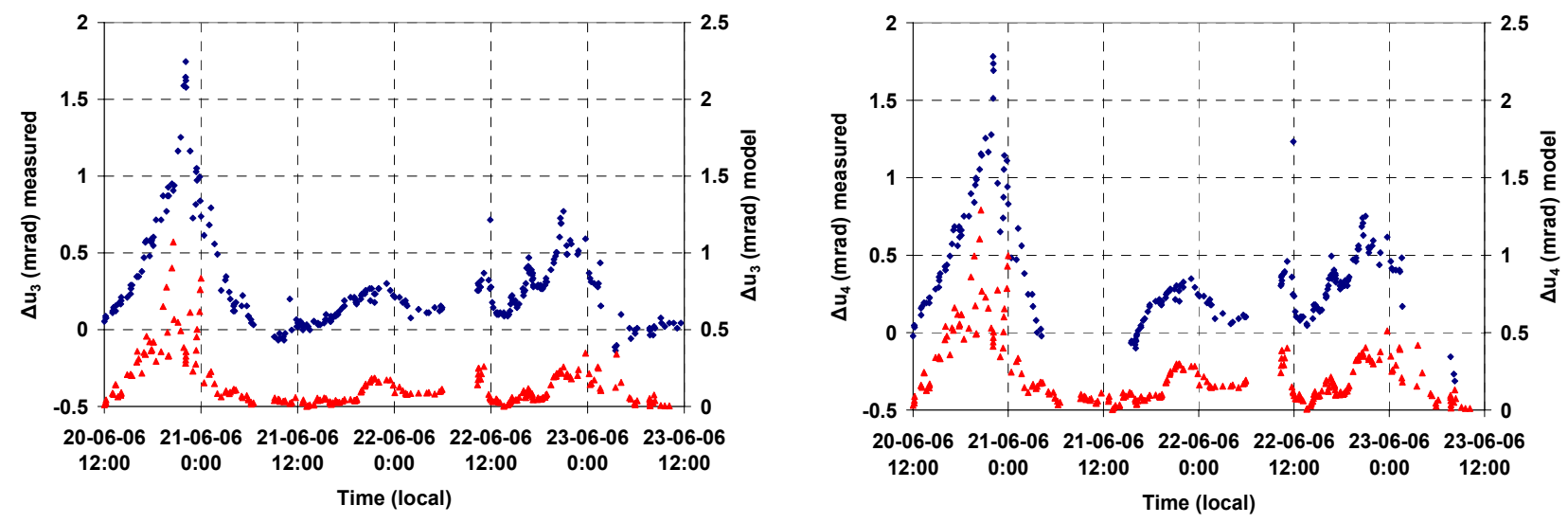

Figure 15. Measured (diamonds) and modeled (formula (1), triangles) values of $\Delta \mathrm{u}_{3}$ (left) and $\Delta \mathrm{u}_{4}$ (right) for POW profile

A more precise but more time consuming method could be applied by running the ray-tracing program for each $\mathrm{T}$ and $\mathrm{T}$ ' combination, time-averaged over a 30 minute periods. The result of such an effort is shown for the data on 20 June for $\Delta \mathrm{u}_{4}$ in Figure 16 (left), where the correspondence between measured and modeled AOA difference is remarkably good. Finally a comparative example is shown of the distortion $\mathrm{D}_{3}$ (the two lowest sources) in Figure 16 (right), for the same part of the trial as taken in Figures 14 and 15. Please note again the shift in the modeled scale. The model calculations show more distortion than the measured one. This corresponds to the result of the $\Delta \mathrm{u}$ calculations for the same sources (see Figure 15), where $\Delta \mathrm{u}_{3}$ is about $60 \%$ of the measured value, while $\Delta \mathrm{u}_{4}$ becomes about $90 \%$ of the measured value.
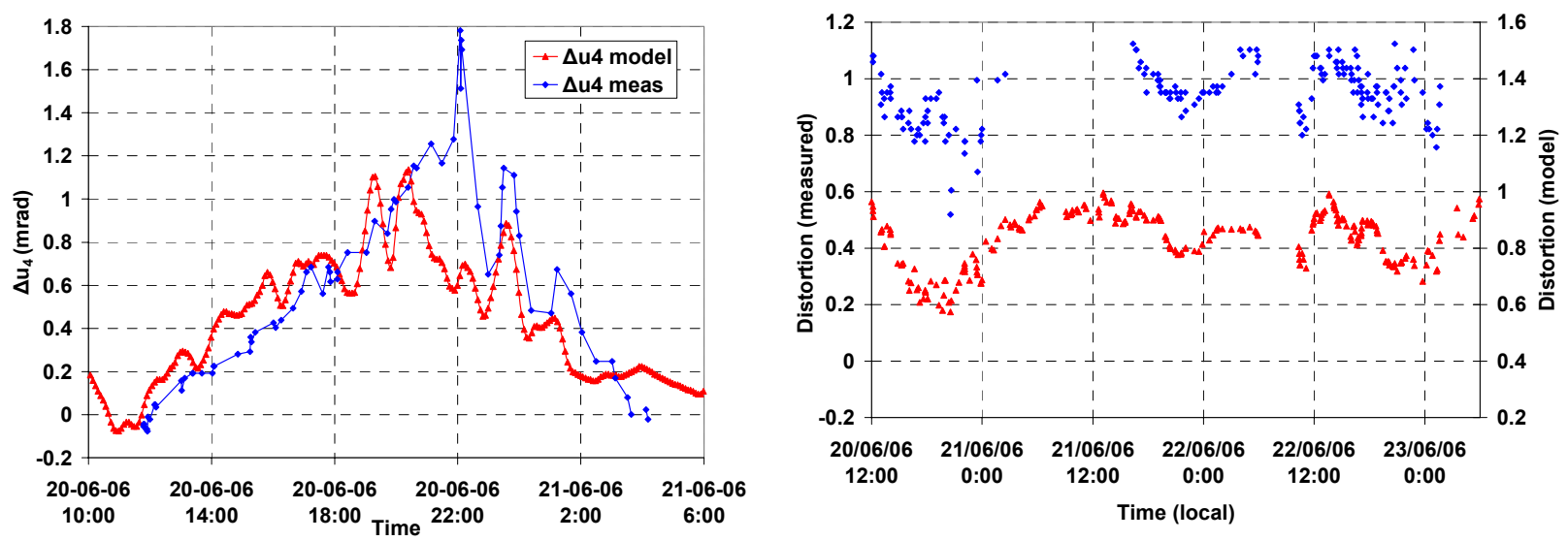

Figure 16. Left: Close-up of $\Delta \mathrm{u}_{4}$ on 20 June with measured data (diamonds) and modeled data (triangles), obtained via precision ray-tracings. Right: Measured and modeled distortion $\mathrm{D}_{3}=\left(\mathrm{u}_{3}-\mathrm{u}_{4}\right) / 0.518$ for part of the trials period

\section{DISCUSSION AND CONCLUSIONS}

The SAPPHIRE trial, carried out in June 2006 over the Chesapeake Bay, has provided a good opportunity for collection of data for validation of optical refraction models in super-refractive conditions. Simultaneously the absolute angle of arrival (AOA) was measured for a set of point sources, and the mid-path temperature T (ASTD) and the gradient T', both at a height of $3.7 \mathrm{~m}$ above water on a buoy. For the sources at a height of 30.9 and $21.4 \mathrm{~m}$, the buoy was not tall enough. A number of different two-parameter temperature profiles were introduced and fitted to the measured values of $\mathrm{T}$ and $\mathrm{T}$ '. Using these profiles, approximate AOA's were calculated for each moment that the AOA's for the four sources were collected via our theodolite instrument. In this way we could compare the AOA's and find out which profile did give the best agreement. For a day with positive $\mathrm{T}$ and $\mathrm{T}$ ' data, precision ray-tracings were carried out. The results confirmed the approximated values and showing a remarkably good correspondence between both sets of AOA differences. 
In particular attention has been given to the temperature profile, generated by the micro-meteorological bulk model, based upon the Monin-Obukhov theory. In this so-called bulk model, used in optical propagation models such as EOSTAR and IRBLEM, one has to insert a set of meteorological parameters. In previous publications it was questioned, if the profiles, predicted by the bulk model in positive ASTD conditions (downward ray bending, super-refraction), were correct. In this paper we have shown, that for the various positive ASTD conditions, occurring during SAPPHIRE, the predicted profile was indeed incorrect, resulting in extreme ray bending for the highest sources. It can be concluded, that the bulk model has to be refined for these conditions. From our investigations the following additional conclusions can be drawn:

- The temperature sensors on the buoy must have a high relative accuracy (better than $0.01 \mathrm{~K}$ )

- Knowledge of the vertical temperature gradient T' with an accuracy of better than $0.01 \mathrm{~K} / \mathrm{m}$ is of higher importance than the absolute value of the ASTD concerning the magnitude of the ray bending

- Temperature measurements on the buoy show occasionally delays with the shore based temperature data, depending on the wind direction

- A daily maximum of the ASTD does not always coincide with a maximum in T-gradient

- Occasionally occurring, periodical fluctuations in the temperature at the buoy are an indication of medium to large scale turbulent motions of the air mass over the Chesapeake Bay

- A set of two-parameter analytical functions to characterize the T-profile and fitted to the measured values of T and T', provide much less ray bending than the T-profile provided via the bulk model

- The use of an auto-level theodolite, giving absolute values of the AOA for each of the point sources, is greatly recommended in optical refraction studies; the cost of the device ( 2000 Euro) should not be an issue

- Simple empirical formulae can be used to approximate the magnitude of $\Delta \mathrm{u}$, being the difference in AOA for each of the sources with the AOA in neutral conditions, with T and T' as input data

- From the analytical T-profiles, the POW profile provides the best fit of the measured and calculated value of $\Delta \mathrm{u}$

- The angular distortion has the highest value for the two lowest sources, while the measured value is smaller than that, predicted via the POW T-profile

- The investigations, described in this paper, based on the data collected during the SAPPHIRE trial, could not be carried out without the support of personnel from NRL, in particular Tom Taczak and Tom Smith; many thanks are indebted to them as well as to Doug Fraedrich and Karin Stein, who organized the trial

\section{REFERENCES}

[1] Denis Dion et al, IR Boundary Layer Effects Model (IRBLEM) version 5.3, DRDC-Valcartier, April 2006

[2] Gerard J. Kunz et al, EOSTAR: an electro-optical sensor performance model for predicting atmospheric refraction, turbulence and transmission in the marine surface layer, SPIE Volume 5237, Optics in Atmospheric Propagation and Adaptive Systems VI, Barcelona, September 2003

[3] S. Pal Arya, Introduction to Micrometeorology, Volume 42 in International Geophysics Series, Academic Press Inc, ISBN 0-12-064490-8, 1988

[4] Arie N. de Jong et al, Atmospheric refraction effects on optical/IR sensor performance in a littoral-maritime environment, Applied Optics, Vol. 43, No. 34, 1 December 2004

[5] Arie N. de Jong, Refraction effects of atmospheric inhomogeneities along the path, SPIE Vol. 5237, International Symposium on Remote Sensing, Barcelona, September 2003

[6] Arie N. de Jong, Enhanced IR point target detection by atmospheric effects, SPIE Vol. 4820, Infrared Technology and Applications XXVIII, Seattle, July 2002

[7] Arie N. de Jong et al, TG16 point target detection experiment POLLEX, Livorno 2001, SPIE Vol. 4820, Infrared Technology and Applications XXVIII, Seattle, July 2002

[8] Dirk Seiffer et al, Variations of apparent target position due to refraction, SPIE Vol. 5981, Optics in Atmospheric Propagation and Adaptive Systems VIII, Bruges, Belgium, September 2005

[9] Denis Dion et al, Prediction of apparent horizon elevation under sub- and super-refractive conditions, SPIE Vol. 5572, Optics in Atmospheric Propagation and Adaptive Systems VII, Gran Canaria, September 2004

[10] Denis Dion et al, Ray-path deviation under stable and unstable conditions, SPIE Vol. 5981, Optics in Atmospheric Propagation and Adaptive Systems VIII, Bruges, Belgium, September 2005 